Article

\title{
SUMOylation Regulates Transcription by the Progesterone Receptor A Isoform in a Target Gene Selective Manner
}

\author{
Hany A. Abdel-Hafiz ${ }^{1,2, *}$, Michelle L. Dudevoir ${ }^{2}$, Daniel Perez ${ }^{2}$, Mohamed Abdel-Hafiz ${ }^{3}$ \\ and Kathryn B. Horwitz ${ }^{2,4}$ \\ 1 Department of Surgery, Anschutz Medical Campus, University of Colorado, 12801 E 17th Avenue, \\ Aurora, CO 80045, USA \\ 2 Department of Medicine, Anschutz Medical Campus, University of Colorado, 12801 E 17th Avenue, \\ Aurora, CO 80045, USA; michelle.dudevoir@ucdenver.edu (M.L.D.); Daniel.Perez@ucdenver.edu (D.P.); \\ Kate.horwitz@ucdenver.edu (K.B.H.) \\ 3 Department of Bioengineering, Anschutz Medical Campus, University of Colorado, 12801 E 17th Avenue, \\ Aurora, CO 80045, USA; Mohamed.abdel-hafiz@ucdenver.edu \\ 4 Department of Pathology, Anschutz Medical Campus, University of Colorado, 12801 E 17th Avenue, \\ Aurora, CO 80045, USA \\ * Correspondence: hany.abdel-hafiz@ucdenver.edu; Tel.: +1-(303)-724-0028; Fax: +1-(303)-724-3162
}

Received: 4 December 2017; Accepted: 29 December 2017; Published: 2 January 2018

\begin{abstract}
Luminal breast cancers express estrogen (ER) and progesterone (PR) receptors, and respond to endocrine therapies. However, some $\mathrm{ER}+\mathrm{PR}+$ tumors display intrinsic or acquired resistance, possibly related to PR. Two PR isoforms, PR-A and PR-B, regulate distinct gene subsets that may differentially influence tumor fate. A high PR-A:PR-B ratio is associated with poor prognosis and tamoxifen resistance. We speculate that excessive PR-A marks tumors that will relapse early. Here we address mechanisms by which PR-A regulate transcription, focusing on SUMOylation. We use receptor mutants and synthetic promoter/reporters to show that SUMOylation deficiency or the deSUMOylase SENP1 enhance transcription by PR-A, independent of the receptors' dimerization interface or DNA binding domain. De-SUMOylation exposes the agonist properties of the antiprogestin RU486. Thus, on synthetic promoters, SUMOylation functions as an independent brake on transcription by PR-A. What about PR-A SUMOylation of endogenous human breast cancer genes? To study these, we used gene expression profiling. Surprisingly, PR-A SUMOylation influences progestin target genes differentially, with some upregulated, others down-regulated, and others unaffected. Hormone-independent gene regulation is also PR-A SUMOylation dependent. Several SUMOylated genes were analyzed in clinical breast cancer database. In sum, we show that SUMOylation does not simply repress PR-A. Rather it regulates PR-A activity in a target selective manner including genes associated with poor prognosis, shortened survival, and metastasis.
\end{abstract}

Keywords: breast cancer; progesterone receptors; SUMOylation; tamoxifen resistance

\section{Introduction}

Actions of progesterone $(\mathrm{P})$ are mediated by two progesterone receptor (PR) isoforms called PR-A and PR-B. They are co-expressed in the normal breast, but equimolarity may be disrupted in breast cancers [1]. The two isoforms have different physiological functions and regulate different sets of genes [1]. In animals, tissue-specific differences in their distribution patterns may account for dissimilar organ-specific P effects [2]. In the mouse mammary gland, PR-B is important for ductal side-branching and the labulo-alveolar development of pregnancy, while PR-A deficiency results in uterine and ovarian abnormalities and infertility. PR-A overexpression leads to abnormal mammary 
gland development including loss of cell-cell adhesion and basement-membrane integrity, suggesting that $\mathrm{P}$ signaling via PR-A contributes to tumorigenesis [3]. Some of the genes regulated only by PR-B and required for normal mammary gland development have been associated with metastasis [4].

In human cells, PR-A controls expression of genes involved in cell adhesion, cell morphology, invasiveness and metastasis, resistance to apoptosis, and tamoxifen resistance [5]. Overexpression of PR-A may promote tumorigenesis and modify responses to tamoxifen, but not to aromatase inhibitors [1]. In vitro and animal studies have shown that exogenous hormones can alter PR-A:PR-B ratios in both normal and malignant cells [6]. Similarly, exposure to exogenous hormones such as with HRT may alter PR-A:PR-B ratios in humans, including in breast cancers [1].

PRs are progestin-activated transcription factors that bind directly to DNA at progesterone response elements (PREs), or bind indirectly by tethering to other DNA-bound factors [7]. The functional differences between the two isoforms are not related to DNA binding since they have equal DNA binding affinities [8]. Rather, since the two isoforms have distinct structural conformations [9], they interact with dissimilar sets of co-regulators on DNA [10]. This is due in part to AF-3 in the unique PR-B upstream sequence and absent in PR-A, which contributes to PR-B's strong transcriptional activity [11,12].

Post-translational modifications such as SUMOylation, acetylation, ubiquitination and phosphorylation modify all nuclear receptors thereby altering their hormone sensitivity, transcriptional activities, protein down-regulation, nuclear localization and protein-protein interactions [13]. Both PRs are post-translationally modified. PR N-termini contain most of the sites subject to modification, including the MAP kinase phosphorylation site Ser294, and the SUMO conjugation site Lys388. PR-B, but not PR-A, are phosphorylated on Ser294 by MAPK and cyclin dependent kinase 2 (CDK2) [14]. PR-B SUMOylation is highly dynamic and hormone-dependent. Disruption of Lys388 by mutation or by deSUMOylation increases the transcriptional activity of PR-B on synthetic PRE-driven promoters suggesting that SUMOylation inhibits transcription [15].

On PR-B, SUMOylation and phosphorylation are independent of one another [15]. However, activation of MAPK and its downstream kinases has complex effects on SUMOylation. For instance, expression of constitutively active MEKK1 has dual effects: it induces SUMOylation of unliganded PR-B but inhibits hormone-dependent PR-B SUMOylation [15]. At all concentrations, MEKK1 increases both basal and hormone-dependent PR-B transcriptional activity, suggesting that its effects on PR-B SUMOylation are indirect. Little is known about the role of SUMOylation on PR-A-dependent transcription of synthetic reporters; its effects on PR-A vs. PR-B function on model reporters; or its role in regulating PR-A vs. PR-B transcription on endogenous genes in breast cancer cells. In this study we address these questions.

\section{Materials and Methods}

\subsection{Plasmids}

Expression vectors for PR-B (pSG5 hPR1) and PR-A (pSG5 hPR2) were a gift of P. Chambon (Strasbourg, France). Cloning of pSG5 hPR1 K388R (PR-B K388R), pSG5 hPR2 K388R (PR-A K388R), hPR2 S294A (PR-AS294A), pSG5 hPR2 R606A (PR-A DX; a DNA dimerization mutant), and constitutively active PCMV-MEKK1 were described previously [7,11]. Construction of $\mathrm{PRE}_{2}-\mathrm{Luc}$ and MMTV-Luc reporter plasmids were described previously [12]. Flag-SENP1 and Flag-SENP1 mutant (R630L, K631M) were gifts of E. Yeh (M. D. Anderson, Houston, TX, USA).

\subsection{Transcription Assays}

HeLa cell transfections were carried out by calcium phosphate co-precipitation as described previously [11]. Briefly, $1.2 \times 10^{5}$ cells were plated in phenol-red free minimum Eagle's medium (MEM) containing 5\% twice charcoal-stripped FBS. Twenty four hours later, cells were washed and treated with the synthetic progestin R5020 (Sigma Chemical Co., St. Louis, MO, USA), the mixed 
agonist/antagonist RU486, or the pure antiprogestin ZK98299 at the final concentrations indicated in the figures. Cells were harvested in lysis buffer (Promega, Madison, WI, USA), and the lysates were analyzed on a dual luminometer. Results were normalized to Renilla luciferase activity and expressed as indicated in the figures.

\subsection{Immunoblotting}

Briefly, for Western blotting [16] whole cell extracts were prepared from transiently transfected HeLa cells treated as indicated in the figures. Following total protein quantification, lysates were separated by SDS-PAGE, transferred to nitrocellulose, and probed with anti-PR PgR1294 (DakoCytomation, Carpinteria, CA, USA) or anti- $\beta$-actin AC-74 (Sigma Chemical Co., St. Louis, MO, USA) monoclonal antibodies. The immunoreactive bands were visualized using the ELC system (PerkinElmer Life Sciences, Houston, TX, USA).

\subsection{Stable Cell Lines}

T47D human breast cancer cells stably expressing WT or SUMOylation-deficient PR-A were created by transfection of previously cloned PR negative T47D-Y cells with expression vectors that encode WT PR-A or PR-AK388R mutant [16,17]. Construction of PR-B expressing cells was previously reported. Cells were maintained in MEM supplemented with 5\% FBS, nonessential amino acids, $25 \mathrm{U} / \mathrm{mL}$ penicillin and $25 \mu \mathrm{g} / \mathrm{mL}$ streptomycin, and $5 \mathrm{ng} / \mathrm{mL}$ insulin. All cell lines have been authenticated by short tandem repeat analysis and are routinely confirmed to be mycoplasma-free.

\subsection{Microarray Analysis}

For gene expression profiling [18], PR-negative T47D-Y cells (no PR), plus derived cells stably expressing WT PR-A or the RPR-A K388 mutant, were cultured as above in vehicle control or $10 \mathrm{nM}$ R5020 for 24 h. Total RNA was extracted (RNAeasy; Qiagen, Baltimore, MD, USA), cRNA was labeled and hybridized to U133 Plus 2 microarrays (Affymetrix, Santa Clara, CA, USA) as described [18]. Partek Genomics Suite 6.0 (Partek Inc., Palo Alto, CA, USA) was used to normalize raw data followed by ANOVA to identify genes differentially expressed among groups in a significant manner. A gene was considered significantly changed, if it had an adjusted $p<0.05$ and fold-change $\geq 1.5$. Heat maps and Venn diagrams were generated using Partek Suite 6.0. Ingenuity Pathway Analysis was used to identify biological processes enriched for differentially expressed genes. All microarray data have been deposited in the Gene Expression Omnibus Database (accession number GSE108607 (http/ / www.ncbi. nlm.nih.gov/geo)).

\subsection{Gene Expression in Human Tumor Samples}

The correlation between gene expression and survival in breast tumors was analyzed by Kaplan-Meier survival analysis (http:// kmplot.com/analysis). We compared patient tumors that highly express the selected differentially regulated genes to ones with low expression and restricted the analysis to luminal subtypes that express ER and PR or were ER-/PR-. The hazard ratio with $95 \%$ confidence intervals and log rank $p$-value were computed. To carry out the comparative analysis between normal and tumor, we used the publicly available Oncomine database to find the status of differentially regulated genes in breast cancer vs. normal (www.oncomine.org) and used the differential analysis "cancer vs. normal" tool. The setting used for the searches were ATAD2, SPINT3, CDKN1c, and CLDN8; cancer type: Breast.

\section{Results}

\subsection{SUMOylation Suppresses PR Transcriptional Activity in a Promoter Dependent Manner}

Downstream of aa165, PR-A and PR-B share post-translational modifications sites including ones for hormone-dependent phosphorylation (Ser294 and Ser345), SUMO conjugation (Lys388), 
and acetylation (KxKK at aa 638-641) (Figure 1A). PR-B SUMOylation is hormone-dependent and suppresses receptor-driven transcription on multiple PREs but not on a single PRE or on MMTV [15]. DeSUMOylation by mutation of PR-B Lys388 promotes transcriptional synergy with other factors on complex promoters. Since PR-A lacks the 165aa "B-upstream segment" (BUS) containing activation function 3 (AF-3), we conjectured that PR-A might not be subject to transcriptional synergy. We therefore compared effects of SUMOylation/deSUMOylation in HeLa cells transfected with WT PR-B or WT PR-A, and the PR-BK388R or PR-A K388R SUMOylation deficient mutants. All four were tested for ligand-independent $(-)$ and ligand-dependent $(+)$ transcription using PRE $\mathrm{P}_{2}-\mathrm{Luc}_{\mathrm{C}}$ (Figure 1B) and MMTV-Luc (Figure 1C) and the progestin R5020. There was no ligand-independent activity. In the presence of ligand, compared to their WT counterparts, both PR-B and PR-A SUMO-deficient mutants displayed increases in transcription on PRE 2 -luc (but not MMTV-Luc). Thus AF-3 of PR-B is not involved in de-repressing transcriptional activity mediated by SUMOylation. We confirmed that AF-3 was uninvolved using the PR-BdL140 BUS mutant in which we knocked out AF-3 function [12], by mutating its K388 to yield PR-Bd1140 K388R. This mutant nevertheless still demonstrated transcriptional upregulation, establishing on the full length PR-B molecule that AF-3 was unnecessary (data not shown). Note that while the activity of PR-A remains weak compared to PR-B it is nevertheless raised by deSUMOylation. Overall, based on use of synthetic promoters, this study demonstrates that SUMOylation suppresses transcription by PR-B and PR-A, which is relieved by deSUMOylation.

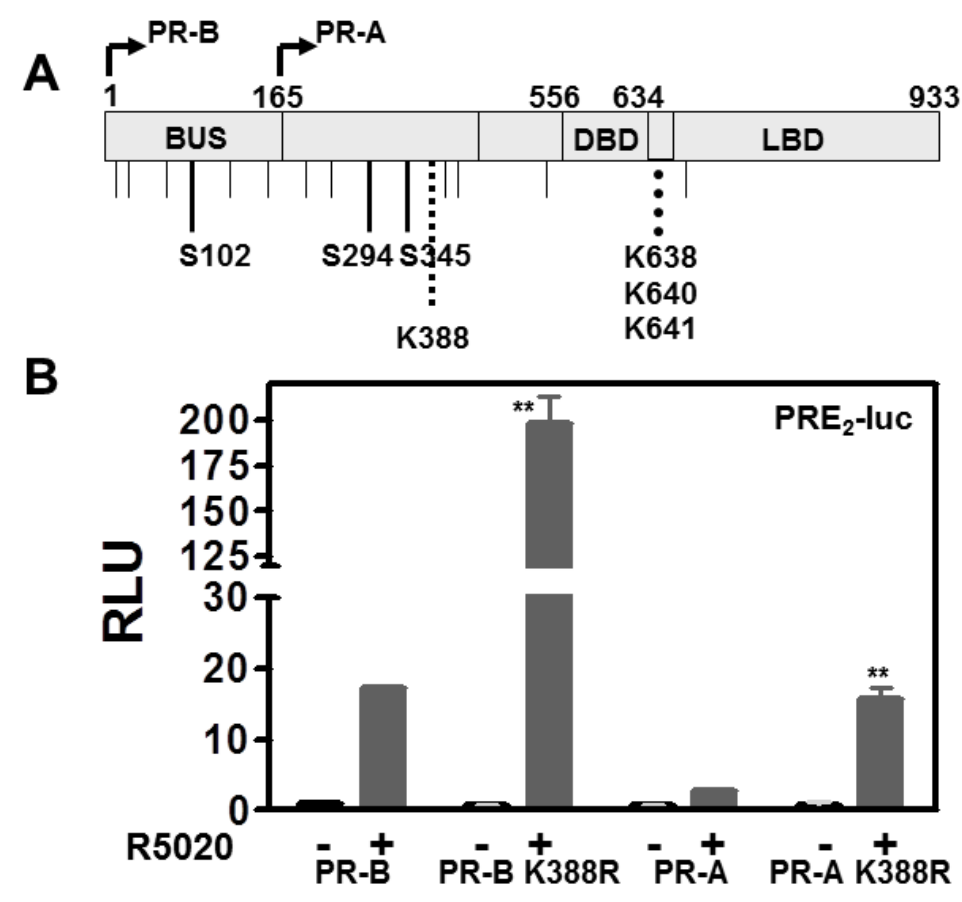

Figure 1. Cont. 


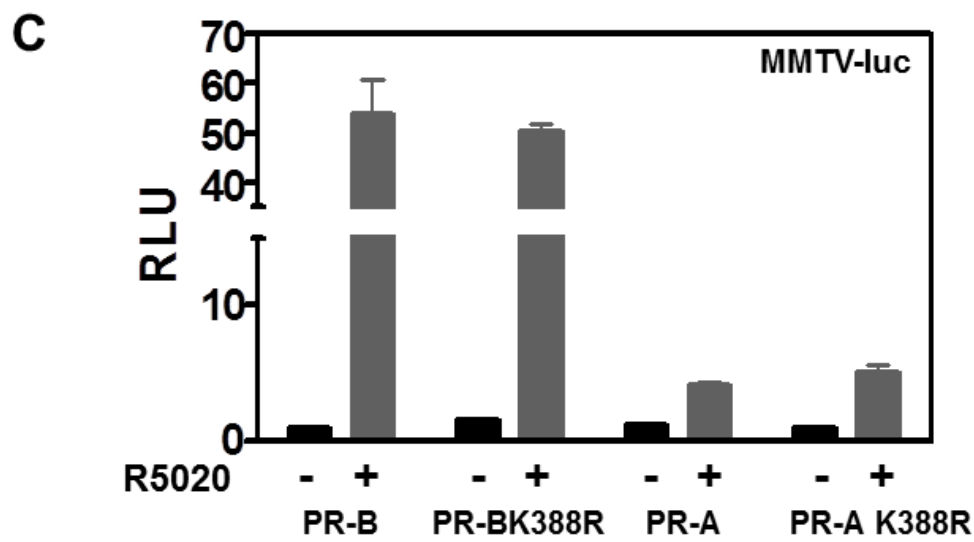

Figure 1. SUMOylation modulates PR transcriptional activity in promoter dependent manner. (A) Schematic representation of the progesterone receptors PR-A and PR-B showing the location of hormone dependent phosphorylation sites (S102, S294 and S345); SUMOylation site (K388); and acetylation site (amino acids 638-641). BUS, B-upstream segment; DBD, DNA binding domain; LBD, ligand binding domain. (B) HeLa cells were transiently transfected with $\mathrm{PRE}_{2}$-luciferase reporter, or (C) MMTV-Luc, together with 50 ng of WT PR-B, mutant PR-B K388R, PR-A, or mutant PR-A K388R expression vectors and Renilla-luciferase as described in Material and Methods. Transfected cells were treated for $24 \mathrm{~h}$ with $10 \mathrm{nM}$ R5020. Luciferase activities are expressed in relative light units (RLU). Data represent triplicates $( \pm \mathrm{SD})$. Statistical significance was computed by unpaired student's $t$ test. ** $p<0.05$.

\subsection{SENP1 deSUMOylates PR-A, Which Enhances Its Transcriptional Activity}

We analyzed SUMOylation in more detail focusing on PR-A. PR-B can be deSUMOylated by SENP1 [15]. Its catalytic function can be inactivated by mutation of Cys603 to yield mSENP1 [19]. We examined SENP1-mediated deSUMOylation of PR-A (Figure 2A) in HeLa cells co-transfected with PR-A, GFP-SUMO1, and either wild type SENP1 or mSENP1, in the absence or presence of R5020. To be SUMOylated, PR-A must be liganded (lanes 1, 3, 5). Liganded PR-A are SUMOylated in the absence of SENP1 (lane 2), remain SUMOylated with mSENP1 (lane 6) but are deSUMOylated by SENP1 (lane 4) demonstrating a role for SENP1 in regulating SUMOylation of PR-A.

Based on Figure 1, this suggested that SENP1 would increase transcription by PR-A. To examine this, transcription of $\mathrm{PRE}_{2}$-Luc was measured in the presence of co-transfected SENP1 or mSENP1 when PR-A were liganded by the agonist R5020, by RU486 (a mixed agonist/antagonist on PR-B but a pure antagonist on PR-A), or by ZK98299, a pure antagonist on both PRs (Figure 2B). In HeLa cells expressing SENP1 or mSENP1, agonist-occupied PR-A are poor trans-activators and the antagonists have no effects. However, PR-A deSUMOylation by SENP1 increases R5020-dependent transcription 10-fold. Remarkably, deSUMOylation exposes the partial agonist properties of RU486 on PR-A; properties that had been reported previously only on PR-B [20]. Note that ZK98299 remains a pure antagonist even on deSUMOylated PR-A. Thus SUMOylation control the agonist/antagonist activity of RU486 liganded PR-A. Parenthetically, this suggests that PR-A may provide a sensitive assay for screening new antiprogestins for any partial agonist activities. In PR-A positive breast cancer cells, co-transfection of SENP1 but not mSENP1 also enhances transcription demonstrating that this effect is not cell specific (not shown).

To confirm that the transcriptional effects in Figure 2B are due directly to PR-A deSUMOylation, a similar study was conducted using the SUMOylation deficient PR-AK388R mutant (Figure 2C). K388R mutant PR-A are completely insensitive to SENP1 demonstrating that the enzymatic effects in Figure 2B require an intact PR-A SUMOylation site. Interestingly, since either PR-A deSUMOylation or mutation of the SUMOylation site expose the partial agonist activity of RU486, both modifications may globally impact PR-A protein structure, thereby altering co-regulator recruitment. 

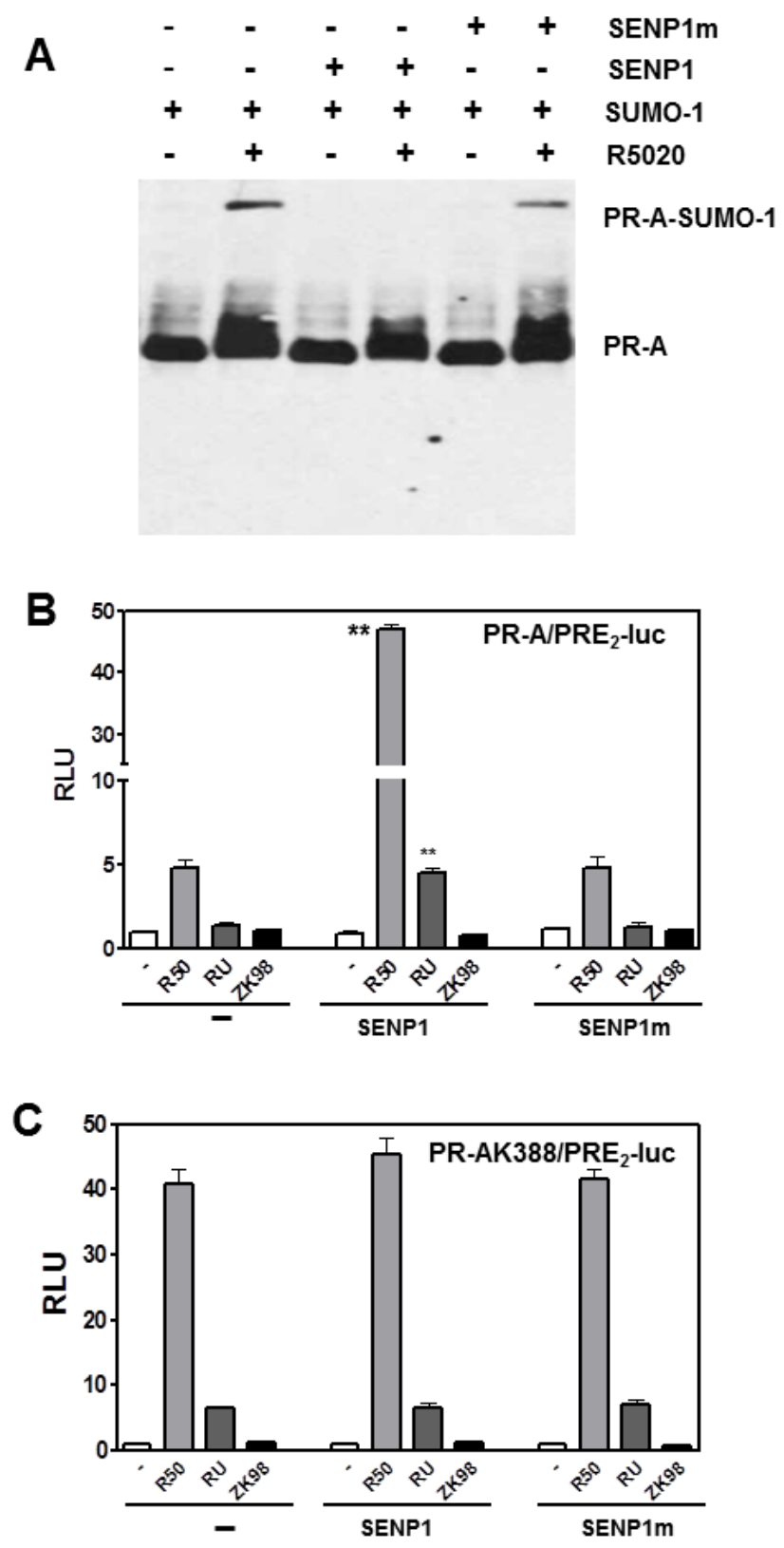

Figure 2. SENP1 deSUMOylates PR-A and enhances its transcriptional activity. (A) HeLa cells were transfected with GFP-SUMO-1, and WT or mutant (m) SENP1 vectors together with WT PR-A. Cells were treated with $10 \mathrm{nM}$ R5020 for $24 \mathrm{~h}$. Cells were lysed and analyzed by western blot for PR-A using anti-PR1294 monoclonal antibody. (B) HeLa cells were transiently transfected with WT PR-A or PR-A K388R, ** $p<0.05$ (C) together with the PRE $_{2}$-luciferase reporter plasmids and 100 ng of Flag-SENP1 or Flag-SENP1m mutant or an empty vector control (-). Transfected cells were treated with the agonist R5020 (R50-10 nM), the partial antagonist RU486 (RU-100 nM), or the pure antagonist ZK 98299 (ZK98-100 nM) for $24 \mathrm{~h}$ before being assayed for luciferase activity as described in Figure 1.

\subsection{The PR DNA Binding Domain (DBD) Dimerization Interface Is Unnecessary for SUMOylation or Transcriptional Control}

Transcription by nuclear receptors is complex, involving post-translational modifications such as SUMOylation, a dimerization interface on the DBD [7,21], and for PR, interactions between the ligand binding domain (LBD) and N-termini to stabilize binding to DNA at multiple PREs [12]. To test the role of DBD dimerization, transcription was quantified on PRE2-luc using PR-A, the PR-A K388R 
mutant as control, and PR-A DX, an R606A mutant of the D-box in the second zinc finger of the DBD [7]. Figure 3A shows that unlike liganded PR-A K388R (lane 4), liganded PR-A DX (lane 6) are SUMOylated to levels equivalent to WT PR-A (lane 2). Thus, SUMOylation/deSUMOylation does not require an intact DBD or theoretically, DNA binding.

Transcription of $\mathrm{PRE}_{2}$ by WT and PR mutants is shown in Figure 3B. SENP1-mediated deSUMOylation strongly activates transcription by R5020-occupied WT PR-A. Mutation of K388 exposes this synergy even in the absence of SENP1. Similar hyper-activation is seen with PR-A DX whether or not it is deSUMOylated by SENP1. This shows that SUMOylation of the DBD dimerization mutant does not inhibit its activity at compound PREs, indicating that DBD dimerization is required downstream of SUMOylation to unmask the inhibitory effects of SUMO.
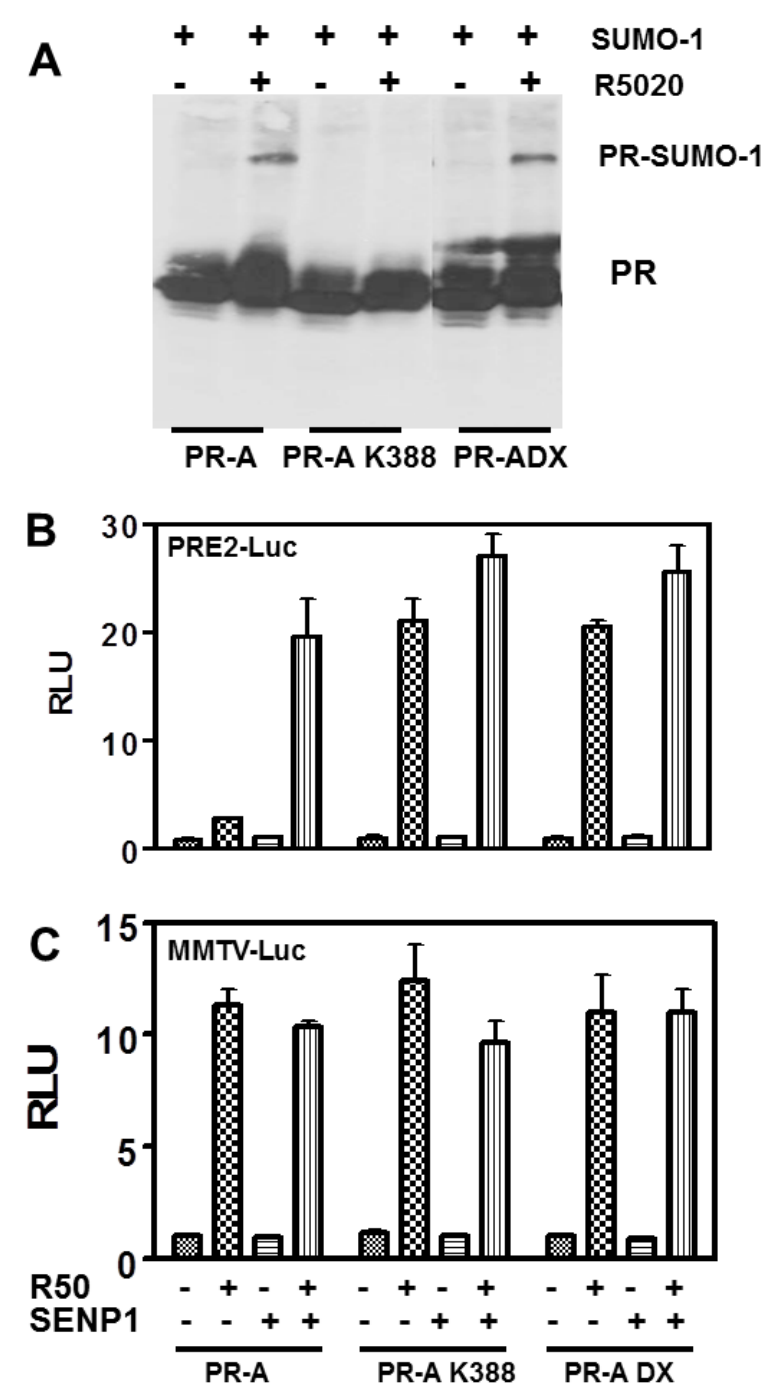

Figure 3. The PR DBD dimerization interface is not necessary for SUMOylation. (A) Western blot analyses were carried out as in Figure 2. HeLa cells were transiently transfected with GFP-SUMO-1, and expression vector encoding WT PR-A, PR-A K388R SUMOylation deficient mutant or DBD dimerization mutant PR-ADX (R606W). Cells were treated for $24 \mathrm{~h}$ with $10 \mathrm{nM}$ R5020. The PR DBD dimerization interface is necessary for effective synergy control. HeLa cells were co-transfected with $2 \mu \mathrm{g}$ of PRE $\mathrm{P}_{2}$-luciferase (B), or MMTV-luciferase (C) reporters, together with $50 \mathrm{ng}$ of a WT PR-A, the PR-A K388R SUMOylation deficient mutant, or a PR-A DBD dimerization mutant (PR-ADX) expression vectors and Renilla-luciferase as an internal control in the presence or absence of $100 \mathrm{ng}$ SENP1 expression vectors. The cells were treated for $24 \mathrm{~h}$ with the agonist R5020 (10 nM), then harvested and lysed. The extracts were assayed for luciferase activities as in Figure 1. 


\subsection{Stimulation of PR-A Ligand-Independent Transcription by MEKK Is Independent of SUMOylation}

To examine effects on transcription from the interplay between phosphorylation and SUMOylation, we compared transcription by WT PR-A, the K388R SUMOylation-deficient mutant, or a S294A phosphorylation-deficient mutant (Figure 4A) in the presence or absence of constitutively active MEKK1. Low MEKK1 expression levels increased hormone-independent and hormone-dependent activities of WT and K388R PR-A. Thus, the stimulatory effect of MEKK1 occurs even on deSUMOylated PR and thus independently of SUMOylation. MEKK1 also stimulated hormone-independent and hormone-dependent transcription of the S294A mutant, demonstrating that MEKK is not acting through this phosphorylation site. Of note, stimulatory effects of MEKK1 are highly concentration dependent. The data in Figure 4B use physiological MEKK1. At pharmacologic concentrations MEKK1 inhibits hormone-dependent PR-A SUMOylation (data not shown); underscoring the importance of dose-response studies in such analyses.

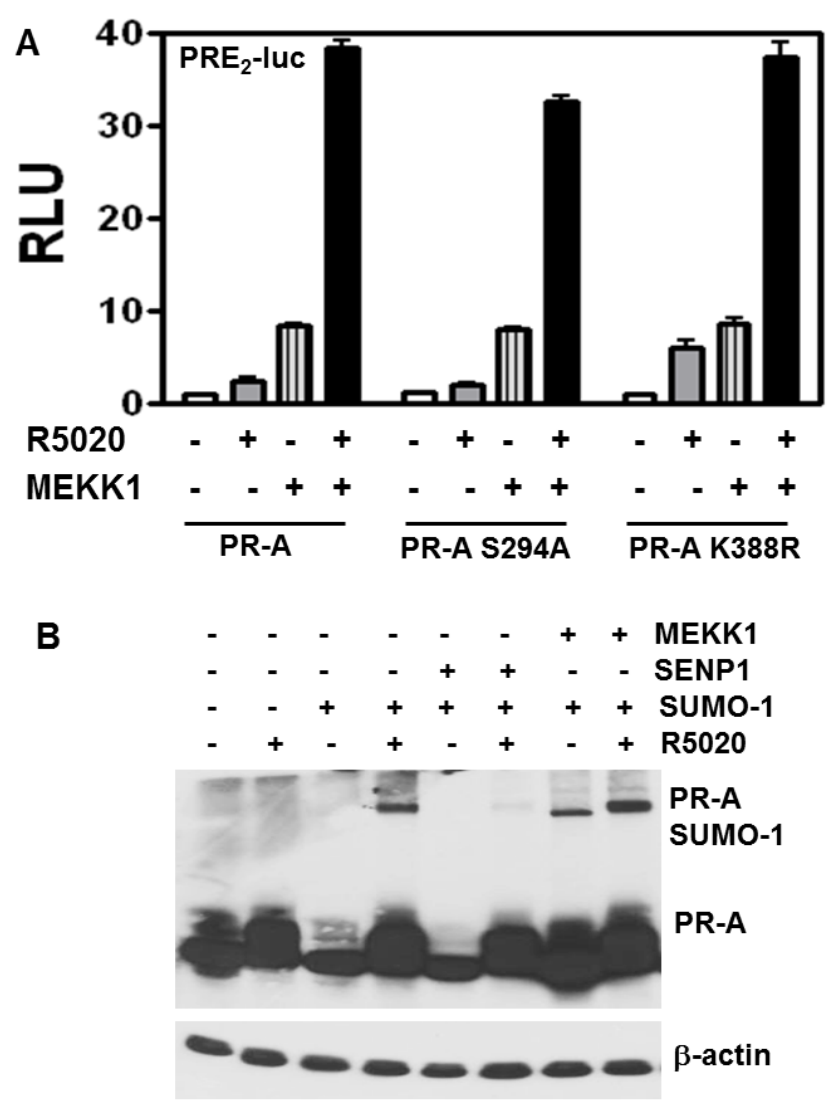

Figure 4. MAP kinase stimulatory effect on PR-A transcriptional activity is independent of the SUMOylation/deSUMOylation. (A) HeLa cells were transfected with $2 \mu \mathrm{g}$ of PRE 2 -luciferase reporters together with 50 ng of WT PR-A, PR-A S294/345 phosphorylation mutant, or PR-A K388R SUMOylation deficient mutant expression vectors and Renilla-Luc as an internal control in the presence or absence of $100 \mathrm{ng}$ constitutively active MEKK1 expression vector. The cells were treated for $24 \mathrm{~h}$ with the agonist R5020 (10 nM) then harvested and lysed. The extracts were assayed for luciferase activities as in Figure 1. (B) DeSUMOylation of PR-A by WT SENP1. HeLa cells were cot-ransfected with PR-A, GFP-SUMO-1 and SENP1 or MEKK1 expression vectors as indicated. Cells were grown in the presence $(+)$ or absence $(-)$ of R5020. PR in cell extracts separated on SDS-PAGE, were detected with anti-PR 1294 monoclonal antibody. $\beta$-actin served as a loading control.

\subsection{Histone Acetylation, SUMOylation and Transcription by PR-A}

Trichostatin A (TSA) alters gene expression by impeding histone deacetylases (HDACs). HDACs have been implicated in transcriptional repression by SUMOylation [22]. To test whether 
HDACs influence SUMO regulation of PR, the transcriptional activities of WT PR-A or PR-A K388R were tested +/ - TSA and +/ - the SUMO de-conjugating enzyme SENP1 (Figure 5A). TSA alone improved transcription by unliganded or liganded PR-A, but to a lesser extent than deSUMOylation by SENP1 (left). TSA plus SENP1 were additive or weakly synergistic, suggesting relatively independent mechanisms of action for acetylation and SUMOylation. This was tested directly with the SUMOylation-deficient mutant (right). Here too, TSA boosted ligand-independent and -dependent transcription. Interestingly at high concentrations (Figure 5B), TSA induced SUMOylation of unliganded PR-A, but inhibited SUMOylation of liganded PR-A; a discordance which confirms that acetylation and SUMOylation are dissociated.

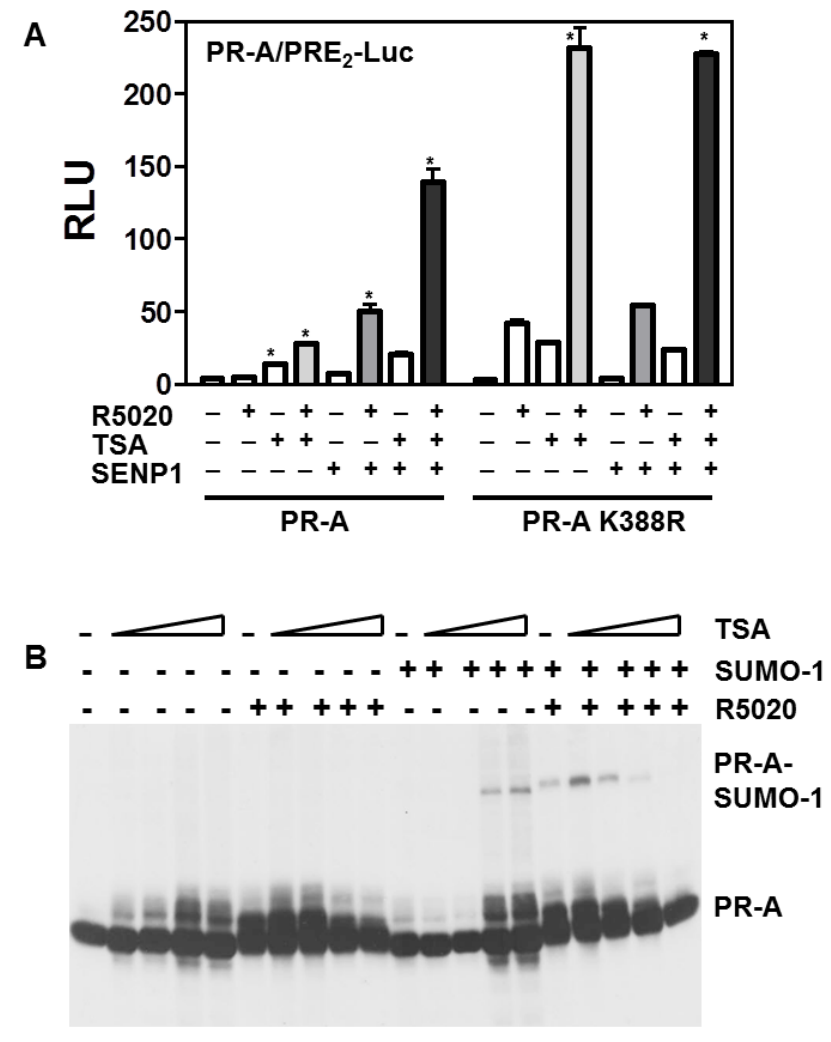

Figure 5. HDACs are not a major target for SENP1 action on PR transcriptional activity. (A) HeLa cells were transfected with $2 \mu \mathrm{g}$ of $\mathrm{PRE}_{2}$-luciferase reporters together with $50 \mathrm{ng}$ of a PR-A (left), or the PR-A K388R mutant (right) expression vectors and Renilla-Luc as an internal control in the presence or absence of $100 \mathrm{ng}$ WT SENP1 expression vectors. The cells were treated for $24 \mathrm{~h}$ with the agonist R5020 (10 nM), without (-) or with (+) 100 nM TSA then harvested and lysed. The extracts were assayed for luciferase activities as in Figure 1. Statistical significance was computed by unpaired student's $t$ test $* p<0.05$. (B) TSA induces ligand-independent PR-A SUMOylation. HeLa cells were transiently transfected with expression vectors encoding WT PR-A in the presence or absence of GFP-SUMO-1. Cells were treated $24 \mathrm{~h}$ without (-) or with (+) $10 \mathrm{nM}$ R5020 in the presence of increasing concentration of TSA. Western blot analysis was performed on cell extracts probed with the anti-PR1294 monoclonal antibodies.

\subsection{SUMOylation Differentially Regulates Endogenous Progestin Target Genes in Breast Cancer Cells}

The above synthetic promoter studies support the conclusion that SUMOylation exerts similar repressive effects on PR-A and PR-B. Can this conclusion be applied to endogenous genes? To answer this, we generated sublines from our previously generated PR-negative T47D-Y breast cancer line, that stably express WT PR-A or K388R PR-A (AKR). Figure 6C shows that T47D-Y are PR-; that the two modified cell lines express similar levels of PR in the absence of R5020; and that receptors in both 
cells undergo normal ligand-dependent down-regulation [16]. Further, both cell lines appropriately activate transcription of $\mathrm{PRE}_{2}$-Luc [16]. Transcript levels of the three untreated, or $24 \mathrm{~h} \mathrm{R}$ 5020-treated, cells were quantified using U133 Plus 2 chips [23]. Unliganded and progestin-regulated genes were grouped by hierarchical clustering into upregulated (red) and down-regulated (blue) genes (Figure 6A). Despite the complexity, statistical analyses resolved 7 distinct gene clusters (Figure 6A). In general Cluster 1 genes are upregulated uniquely by liganded WT PR-A; Cluster 2 genes are upregulated by WT and AKR mutant PR-A; Cluster 3 genes and to a lesser extent Class 4 genes are upregulated mainly by AKR mutant PR-A; Class 5 genes are interesting, apparently down-regulated by both unliganded and liganded WT PR-A; Class 6 genes tend to be down-regulated by liganded WT and mutant PR; Class 7 genes are demonstrably down-regulated mainly by the liganded AKR PR mutants.

Venn diagrams (Figure 6B) quantify progestin-regulated (red and blue) and ligand independent (yellow and grey) genes by WT PR-A or the SUMO-deficient AKR mutant. Four-hundred forty-five (445) genes were R5020-upregulated by both WT and mutant PR-A, 902 were upregulated only by WT PR-A, and 806 were upregulated only by the mutant. R5020-bound WT PR-A uniquely down-regulated 962 genes, the mutant down-regulated 276, and both receptors down-regulated 206. These diagrams clearly demonstrate the variable responses of endogenous genes to progestin-bound PR-A. The lower diagrams in Figure 2B quantify genes down- or upregulated by unliganded PR-A or PR-AK388R. These are of course also of considerable interest as they may modify tumor biology even in the absence of progesterone.

Expression profiling clearly shows that endogenously, SUMOylation modulates PR-A function in a target gene selective fashion, and not by general repression of PR-A activity. While some genes, such as SGK1 and PDK4 are unaffected by SUMOylation, others, such as CDKN1c and Claudin 8 (Figure 7) are only expressed in cells capable of SUMOylating WT PR-A. Expression of other genes, such as NDRG1, is enhanced only in the de-repressed K388R mutant cells, indicating that in WT cells SUMOylation represses NDRG1 activity. We used Ingenuity Pathway Analysis (IPA) to identify cellular functions and pathways significantly enriched by PR-A SUMOylation. The top five diseases were cancer, organismal injury and abnormalities, gastrointestinal disease, reproductive system disease and respiratory disease. The top five molecular and cellular functions were cell cycle, cellular assembly and organization, DNA replication, recombination and repair, cell death or survival, and cellular development (Figure 6D).

Several genes were selected using the Oncomine database, to assess their possible role in patients with breast cancer (Figure 7). ATAD2 and SPINT3 are upregulated by ligand in K388R mutant cells indicating that their expression is normally suppressed by SUMOylated PR (Figure 7(Ai)). Both genes are upregulated in ductal carcinomas (Figure 7(Aii)). Using Kaplan-Meier survival analysis (http:/ / kmplot.com/analysis), we compared tumors that highly express these genes (red) to ones with low expression (black), in ER+/PR+ (Figure 7(Aiii)) or ER-/PR- disease (Figure 7(Aiv)). Significance data and $p$-values are shown in the upper right corner of each box. It is clear that upregulated genes may significantly $(p \leq 0.05)$ correlate with survival in some tumors. CDKN1c and Claudin 8 are strongly upregulated by progestin-occupied, SUMOylated WT PR-A. Receptor deSUMOylation suppresses this regulation. Interestingly, these genes are strikingly suppressed in ductal carcinomas and their expression may also correlate with tumor behavior. In general, we hypothesize that besides acting as markers, PRs and their SUMOylation/deSUMOylation state may play a functional role in tumor survival. 


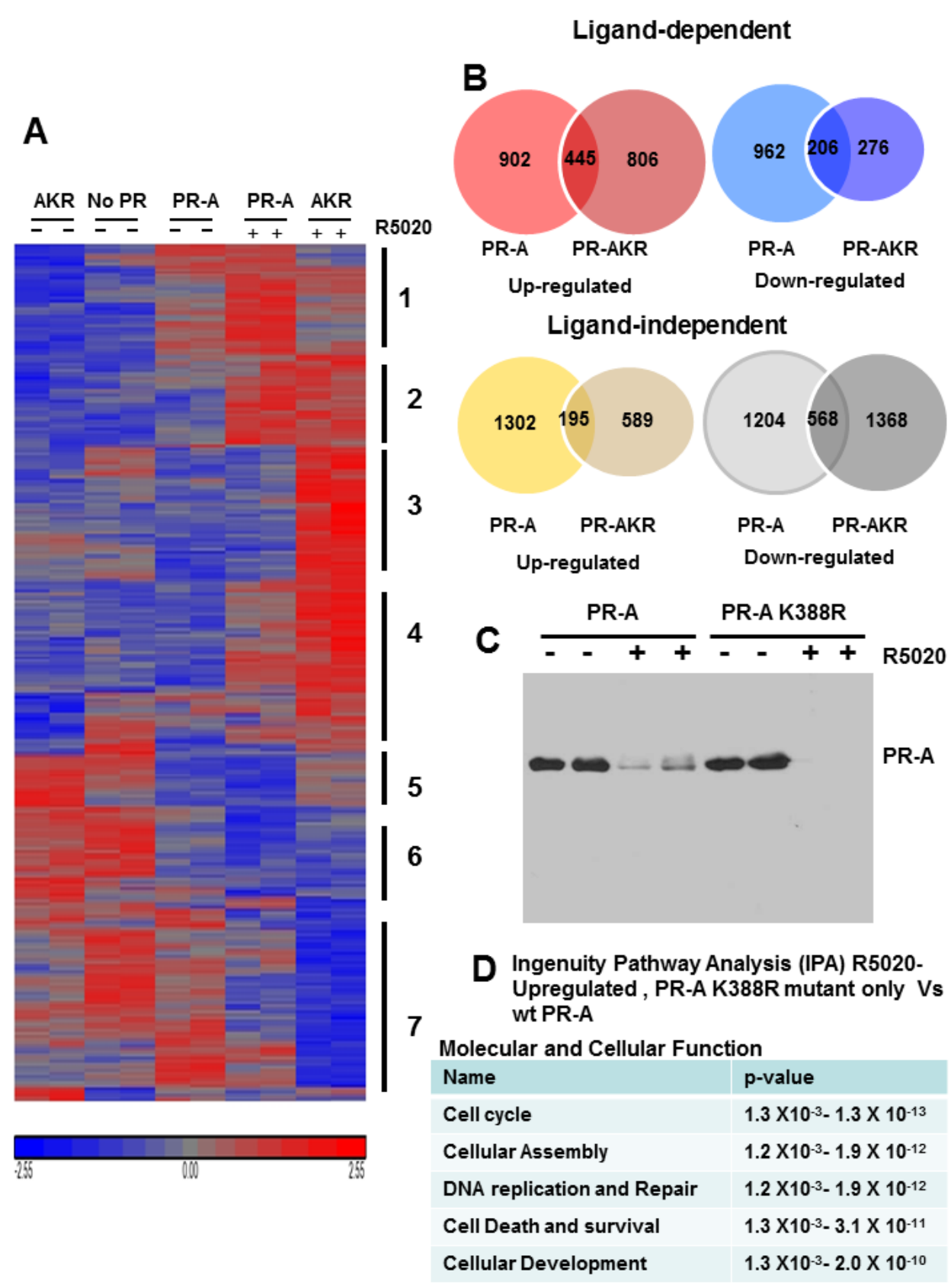

Figure 6. PR-A SUMOylation regulates the expression of endogenous genes. T47D stably transfected breast cancer cell lines with WT PR-A or PR-A K388R (AKR) SUMOylation deficient mutant were treated with $10 \mathrm{nM}$ synthetic progestin R5020 (+) or vehicle for $24 \mathrm{~h}$ and isolated RNAs were analyzed by U133 Plus 2 microarray as described in "materials and methods". (A) Heat map of R5020-regulated genes clustered by hierarchical clustering using Partek Genomics Suite 6.0. (B) Venn diagrams showing hormone-dependent up or down-regulated genes (upper panel) and hormone-independent up and down-regulated genes (lower panel). (C) Western blot shows the expression of WT PR-A or PR-A K388R SUMOylation deficient mutant in the presence (+) or absence (-) of $10 \mathrm{nM}$ R5020. (D) Ingenuity pathway analysis (IPA) showing the top molecular and cellular functions that were the most significantly enriched for R5020-upregulated genes differently expressed between PR-A K388R mutant and WT PR-A cells. 
ATAD2

\section{A- PR-A K388R hormone dependent upregulated genes}
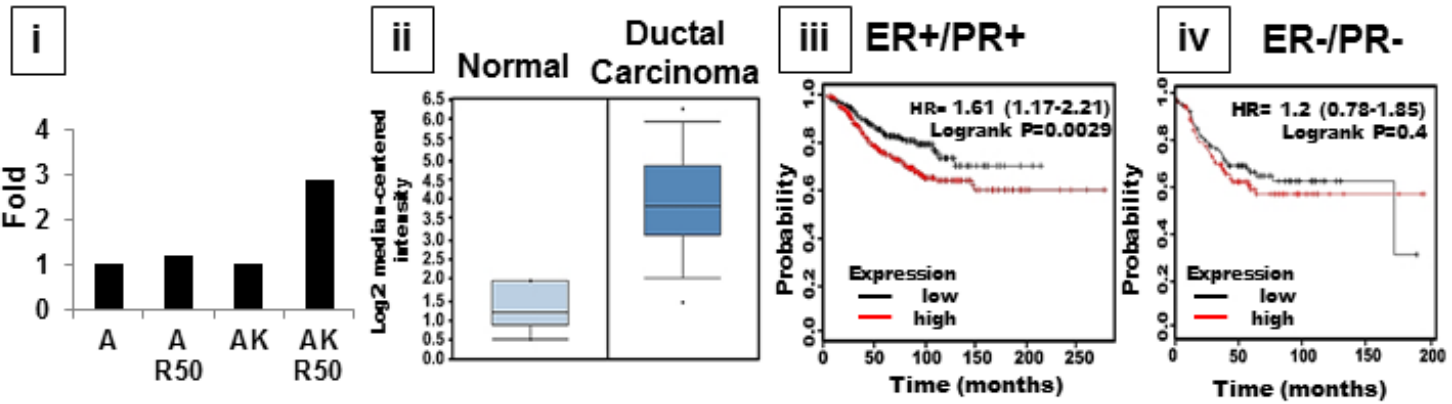

\section{SPINT3}

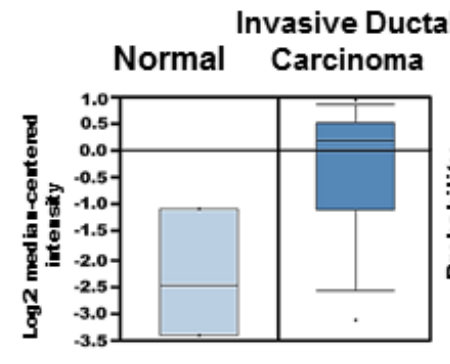

ER+/PR+

ER-IPR-
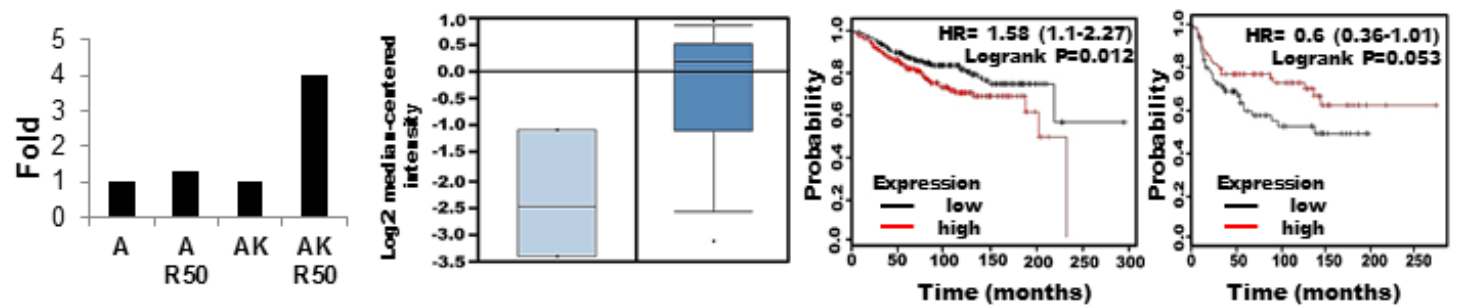

CDKN1c

B- PR-A hormone dependent upregulated genes
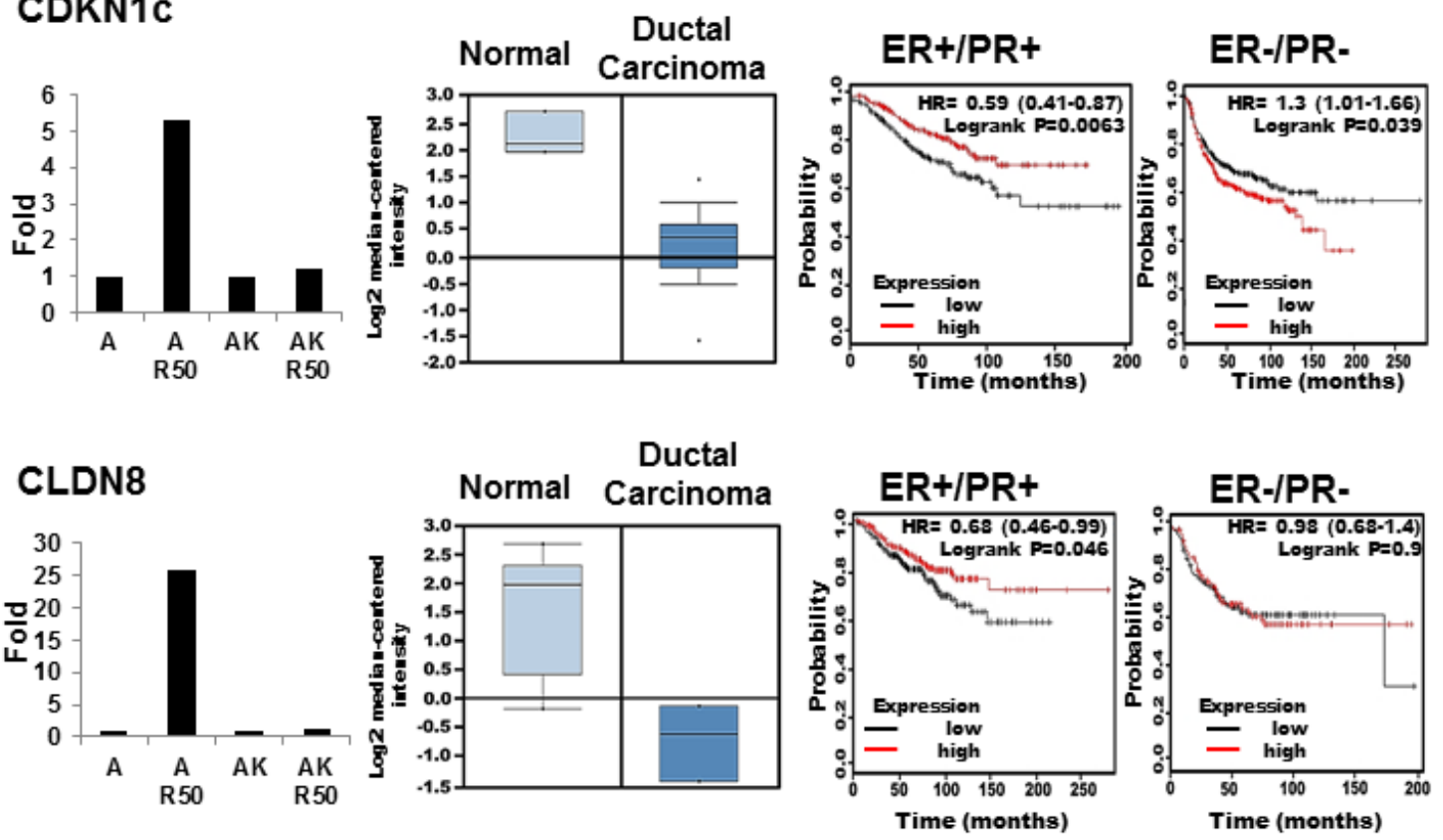

Figure 7. PR-A SUMOylation plays a functional role in tumor survival. Hormone dependent gene expression by PR-A K399R (A) or PR-A (B). Relative expression levels of ATAD2, SPINTS3, CDKN1c, and CLDN8 (PR-A target genes) in T47D breast cancer cells that stably express WT PR-A or PR-A K388R (i), and in breast cancer patient cohorts (ii) (Oncomine database). Kaplan-Meier survival curves showing relationship between high (red line) and low levels (black line) of target gene expression and overall survival in patients with ER-positive tumors (iii) or ER-negative tumors (iv). Statistical data are show in the upper right corner of each box with $p \leq 0.05$ considered significant. 


\section{Discussion}

$\mathrm{ER}+/ \mathrm{PR}+$ tumors respond better to endocrine therapies than ER+/PR- ones but PR levels are not necessarily related to benefit, raising questions about appropriate PR "cut-off" levels in clinical assays. Additionally, besides simply acting as markers of hormone responsiveness, PR signaling undoubtedly has functional consequences in both liganded and unliganded states. The receptors are extensively modified post-translationally, which influences their gene regulatory capacity including crosstalk with ER [24,25]. For instance it is not always appreciated that PR can inhibit ER transcriptional activity $[11,24]$.

Moreover, all $\mathrm{P}$ target tissues express two PR isoforms, which regulate different sets of genes with different downstream sequelae [4]. PR-B but not PR-A are required for mammary gland development and expansion [26]. RANKL, a gene activated only by PR-B [27], plays an important role in the pregnant mammary gland; in initiation and progression of P-induced breast cancer [28]; and for maintenance and expansion of mammary stem cells [29]. The structural and functional mechanisms underlying differences between PR-A and PR-B are under active investigation. With respect to structure, we find that we can completely destroy the AF-3 transcriptional function unique to the $\mathrm{N}$-terminal region of PR-B, without converting the mutant to PR-A. Differences in function are unrelated to DNA binding affinity since both receptors bind DNA equally well. Rather, it appears that functional differences are dependent on recruitment of different coactivators to the two DNA-bound receptors [30]. This recruitment in turn is controlled by post-translational modifications of the receptors, including their phosphorylation, ubiquitination, acetylation and SUMOylation states. Here we focus on SUMOylation of PR-A, and examine phosphorylation and acetylation, to analyze the consequences of these modifications on transcription of synthetic promoter/reporters, and also on transcription of endogenous genes in human breast cancer cells. The latter have rarely been assessed.

We use PR-negative human breast cancer cells that we isolated, then modified to stably express WT PR-A, a SUMOylation deficient PR-A K388R mutant to model SUMOylation failure, plus other mutants. We also use various concentrations of enzymes that de-SUMOylate the receptors or drugs that target phosphorylation or acetylation. With regard to SUMOylation, our analyses indicate that this modification does not simply attenuate PR activity on all target genes as has been concluded from use of synthetic promoters. Instead endogenously, PR SUMOylation controls whether the receptors either liganded or unliganded, up- or down-regulate genes, or lose regulatory capacity altogether. This endogenous complexity is consistent with previous reports for PR-B, and for glucocorticoid (GR) and androgen (AR) receptors, which also show SUMO-sensitive target-selectivity [31].

We report pathway analysis to identify genes differentially regulated by SUMOylated vs. deSUMOylated PR-A, and find that the dominant genes are involved in molecular and cellular functions of the cell cycle, cellular assembly and organization, DNA replication, recombination and repair, cell death/survival, and cellular development. The top genes upregulated by liganded but deSUMOylated PR-A (i.e., genes that are normally repressed by receptor SUMOylation) are associated with brain metastasis, poor overall survival and poor prognosis. Among these are: ATAD2, ADAMTS8, DIO2, KCNMA, and NOK1. Briefly, ATAD2 is a nuclear coactivator of ER and AR crucial for assembly of chromatin-modifying complexes and proliferation of hormone-responsive cancer cells [32]. Its overexpression correlates with aggressiveness of breast and endometrial cancers [33] via recruitment of the coactivator SRC3 [34]. ADAMTS8 is also a predictor of poor overall survival [35]. $\mathrm{DIO} 2$ activates thyroid hormone and plays a role in P/PR-induced proliferation [36]. KCNMA1 is a pore forming $\alpha$-subunit of the large-conductance calcium- and voltage-activated potassium channel linked to heightened proliferation and brain metastases [37]. NOK is a potent oncogene expressed in multiple cancers [38], which activates signaling pathways including MAPK and PI3K by phosphorylating them [39]. Clearly, all these genes are important and subject to complex regulation, among which are the "repressor" effects of SUMOylated PR-A.

Then, we find genes that require liganded SUMOylated PR-A for their upregulation. One is CDKN1C-p57Kip2 (Figure 7), a protein reduced or lost in the majority of breast cancers, possibly 
through ER-dependent mechanisms. Similarly, Claudin 8 (CLDN8), a tight junction protein dysregulated in a number of cancers [40], is down-regulated in ductal carcinomas compared to the normal breast (Figure 7) and is associated with differential survival of patients with ER+/PR+vs. $\mathrm{ER}-/ \mathrm{PR}-$ disease. Another interesting gene in this category is $\mathrm{C} / \mathrm{EBP} \delta$, an inflammatory response gene and tumor suppressor associated with metastasis [41]. Other genes uniquely upregulated by SUMOylated PR-A include ALDH1A3 (4.5-fold), Annexin A1 (5.6-fold) and ERR $\gamma$, an estrogen-related receptor induced 26.2-fold. All are associated with poor patient survival, triple negative disease and tamoxifen resistance, and all are examples of genes that are not suppressed by PR-A SUMOylation.

In sum, our studies address PR structural regions and signaling pathways involved in post-translational PR-A modifications, focused on transcriptional regulation by SUMOylation. We demonstrate that the mixed progestin/antiprogestin RU486, used to terminate early pregnancy by blocking P-activated PRs, loses its antagonist properties on de-SUMOylated receptors. This is an interesting example of how a receptor's SUMOylation state modifies the target specificity of a bound hormone. Parenthetically, this suggests use of SUMO-deficient PR-A as a sensitive assay for screening new antiprogestins for their partial agonist activities. Only a pure antiprogestin would be inactive on de-SUMOylated PR-A. We also show that the PR-A SUMOylation state controls not only the transcriptional potency of these receptors, but also the direction, both up and down, in which endogenous genes are progestin-regulated through PR-A. These issues need to be understood, especially in premenopausal women, as SUMO-modifying drugs enter mainstream medical practice for treatment of cancers, cardiac disease, neurodegenerative diseases, viral infections, and the like [42].

Acknowledgments: We greatly appreciate the gifts of reagents from several colleagues described in Experimental Procedures. These studies were funded by the NIH, NCI CA026869-35; the National Foundation for Cancer Research; the Breast Cancer Research Foundation; and the Avon Foundation for Women.

Author Contributions: H.A.A.-H. and K.B.H. conceived and designed the experiments; H.A.A.-H., M.L.D. and D.P. performed the experiments; H.A.A.-H. and M.A.-H. analyzed the data; H.A.A.-H. and K.B.H. contributed reagents/materials/analysis tools; H.A.A.-H., M.A.-H. and K.B.H. wrote the paper.

Conflicts of Interest: The authors declare no conflict of interest.

\section{References}

1. Mote, P.A.; Gompel, A.; Howe, C.; Hilton, H.N.; Sestak, I.; Cuzick, J.; Dowsett, M.; Hugol, D.; Forgez, P.; Byth, K.; et al. Progesterone receptor A predominance is a discriminator of benefit from endocrine therapy in the ATAC trial. Breast Cancer Res. Treat. 2015, 151, 309-318. [CrossRef] [PubMed]

2. Scarpin, K.M.; Graham, J.D.; Mote, P.A.; Clarke, C.L. Progesterone action in human tissues: Regulation by progesterone receptor (PR) isoform expression, nuclear positioning and coregulator expression. Nucl. Recept. Signal. 2009, 7, e009. [CrossRef] [PubMed]

3. Shyamala, G.; Yang, X.; Cardiff, R.D.; Dale, E. Impact of progesterone receptor on cell-fate decisions during mammary gland development. Proc. Natl. Acad. Sci. USA 2000, 97, 3044-3049. [CrossRef] [PubMed]

4. Richer, J.K.; Jacobsen, B.M.; Manning, N.G.; Abel, M.G.; Wolf, D.M.; Horwitz, K.B. Differential gene regulation by the two progesterone receptor isoforms in human breast cancer cells. J. Biol. Chem. 2002, 277, 5209-5218. [CrossRef] [PubMed]

5. McFall, T.; McKnight, B.; Rosati, R.; Kim, S.; Huang, Y.; Viola-Villegas, N.; Ratnam, M. Progesterone Receptor A Promotes Invasiveness and Metastasis of Luminal Breast Cancer by Suppressing Regulation of Critical Micro RNAs by Estrogen. J. Biol. Chem. 2017. [CrossRef] [PubMed]

6. Isaksson, E.; Wang, H.; Sahlin, L.; von Schoultz, B.; Cline, J.M.; von Schoultz, E. Effects of long-term HRT and tamoxifen on the expression of progesterone receptors A and B in breast tissue from surgically postmenopausal cynomolgus macaques. Breast Cancer Res. Treat. 2003, 79, 233-239. [CrossRef] [PubMed]

7. Jacobsen, B.M.; Jambal, P.; Schittone, S.A.; Horwitz, K.B. ALU repeats in promoters are position-dependent co-response elements (coRE) that enhance or repress transcription by dimeric and monomeric progesterone receptors. Mol. Endocrinol 2009, 23, 989-1000. [CrossRef] [PubMed] 
8. Onate, S.A.; Prendergast, P.; Wagner, J.P.; Nissen, M.; Reeves, R.; Pettijohn, D.E.; Edwards, D.P. The DNA-bending protein HMG-1 enhances progesterone receptor binding to its target DNA sequences. Mol. Cell. Biol. 1994, 14, 3376-3391. [CrossRef] [PubMed]

9. Bain, D.L.; Franden, M.A.; McManaman, J.L.; Takimoto, G.S.; Horwitz, K.B. The N-terminal region of human progesterone B-receptors: Biophysical and biochemical comparison to A-receptors. J. Biol. Chem. 2001, 276, 23825-23831. [CrossRef] [PubMed]

10. Tetel, M.J.; Giangrande, P.H.; Leonhardt, S.A.; McDonnell, D.P.; Edwards, D.P. Hormone-dependent interaction between the amino- and carboxyl-terminal domains of progesterone receptor in vitro and in vivo. Mol. Endocrinol. 1999, 13, 910-924. [CrossRef] [PubMed]

11. Abdel-Hafiz, H.; Takimoto, G.S.; Tung, L.; Horwitz, K.B. The inhibitory function in human progesterone receptor $\mathrm{N}$ termini binds SUMO-1 protein to regulate autoinhibition and transrepression. J. Biol. Chem. 2002, 277, 33950-33956. [CrossRef] [PubMed]

12. Tung, L.; Abdel-Hafiz, H.; Shen, T.; Harvell, D.M.; Nitao, L.K.; Richer, J.K.; Sartorius, C.A.; Takimoto, G.S.; Horwitz, K.B. Progesterone receptors (PR)-B and -A regulate transcription by different mechanisms: AF-3 exerts regulatory control over coactivator binding to PR-B. Mol. Endocrinol. 2006, 20, 2656-2670. [CrossRef] [PubMed]

13. Daniel, A.R.; Gaviglio, A.L.; Czaplicki, L.M.; Hillard, C.J.; Housa, D.; Lange, C.A. The progesterone receptor hinge region regulates the kinetics of transcriptional responses through acetylation, phosphorylation, and nuclear retention. Mol. Endocrinol. 2010, 24, 2126-2138. [CrossRef] [PubMed]

14. Knutson, T.P.; Daniel, A.R.; Fan, D.; Silverstein, K.A.; Covington, K.R.; Fuqua, S.A.; Lange, C.A. Phosphorylated and sumoylation-deficient progesterone receptors drive proliferative gene signatures during breast cancer progression. Breast Cancer Res. 2012, 14, R95. [CrossRef] [PubMed]

15. Abdel-Hafiz, H.A.; Horwitz, K.B. Control of progesterone receptor transcriptional synergy by SUMOylation and deSUMOylation. BMC Mol. Biol. 2012, 13, 10. [CrossRef] [PubMed]

16. Abdel-Hafiz, H.; Dudevoir, M.L.; Horwitz, K.B. Mechanisms underlying the control of progesterone receptor transcriptional activity by SUMOylation. J. Biol. Chem. 2009, 284, 9099-9108. [CrossRef] [PubMed]

17. Sartorius, C.A.; Groshong, S.D.; Miller, L.A.; Powell, R.L.; Tung, L.; Takimoto, G.S.; Horwitz, K.B. New T47D breast cancer cell lines for the independent study of progesterone B- and A-receptors: Only antiprogestin-occupied B-receptors are switched to transcriptional agonists by cAMP. Cancer Res. 1994, 54, 3868-3877. [PubMed]

18. Badtke, M.M.; Jambal, P.; Dye, W.W.; Spillman, M.A.; Post, M.D.; Horwitz, K.B.; Jacobsen, B.M. Unliganded progesterone receptors attenuate taxane-induced breast cancer cell death by modulating the spindle assembly checkpoint. Breast Cancer Res. Treat. 2012, 131, 75-87. [CrossRef] [PubMed]

19. Cheng, J.; Wang, D.; Wang, Z.; Yeh, E.T. SENP1 enhances androgen receptor-dependent transcription through desumoylation of histone deacetylase 1. Mol. Cell. Biol. 2004, 24, 6021-6028. [CrossRef] [PubMed]

20. Tung, L.; Mohamed, M.K.; Hoeffler, J.P.; Takimoto, G.S.; Horwitz, K.B. Antagonist-occupied human progesterone B-receptors activate transcription without binding to progesterone response elements and are dominantly inhibited by A-receptors. Mol. Endocrinol. 1993, 7, 1256-1265. [CrossRef] [PubMed]

21. Iniguez-Lluhi, J.A.; Pearce, D. A common motif within the negative regulatory regions of multiple factors inhibits their transcriptional synergy. Mol. Cell. Biol. 2000, 20, 6040-6050. [CrossRef] [PubMed]

22. Yang, S.H.; Sharrocks, A.D. SUMO promotes HDAC-mediated transcriptional repression. Mol. Cell 2004, 13, 611-617. [CrossRef]

23. Harvell, D.M.; Kim, J.; O’Brien, J.; Tan, A.C.; Borges, V.F.; Schedin, P.; Jacobsen, B.M.; Horwitz, K.B. Genomic signatures of pregnancy-associated breast cancer epithelia and stroma and their regulation by estrogens and progesterone. Horm. Cancer 2013, 4, 140-153. [CrossRef] [PubMed]

24. Mohammed, H.; Russell, I.A.; Stark, R.; Rueda, O.M.; Hickey, T.E.; Tarulli, G.A.; Serandour, A.A.; Birrell, S.N.; Bruna, A.; Saadi, A.; et al. Progesterone receptor modulates ERalpha action in breast cancer. Nature 2015, 523, 313-317. [CrossRef] [PubMed]

25. Finlay-Schultz, J.; Gillen, A.E.; Brechbuhl, H.M.; Ivie, J.J.; Matthews, S.B.; Jacobsen, B.M.; Bentley, D.L.; Kabos, P.; Sartorius, C.A. Breast Cancer Suppression by Progesterone Receptors Is Mediated by Their Modulation of Estrogen Receptors and RNA Polymerase III. Cancer Res. 2017, 77, 4934-4946. [CrossRef] [PubMed] 
26. Conneely, O.M.; Mulac-Jericevic, B.; Lydon, J.P.; De Mayo, F.J. Reproductive functions of the progesterone receptor isoforms: Lessons from knock-out mice. Mol. Cell. Endocrinol. 2001, 179, 97-103. [CrossRef]

27. Mulac-Jericevic, B.; Lydon, J.P.; DeMayo, F.J.; Conneely, O.M. Defective mammary gland morphogenesis in mice lacking the progesterone receptor B isoform. Proc. Natl. Acad. Sci. USA 2003, 100, 9744-9749. [CrossRef] [PubMed]

28. Azim, H.A., Jr.; Peccatori, F.A.; Brohee, S.; Branstetter, D.; Loi, S.; Viale, G.; Piccart, M.; Dougall, W.C.; Pruneri, G.; Sotiriou, C. RANK-ligand (RANKL) expression in young breast cancer patients and during pregnancy. Breast Cancer Res. 2015, 17, 538. [CrossRef] [PubMed]

29. Joshi, P.A.; Jackson, H.W.; Beristain, A.G.; Di Grappa, M.A.; Mote, P.A.; Clarke, C.L.; Stingl, J.; Waterhouse, P.D.; Khokha, R. Progesterone induces adult mammary stem cell expansion. Nature 2010, 465, 803-807. [CrossRef] [PubMed]

30. Roemer, S.C.; Donham, D.C.; Sherman, L.; Pon, V.H.; Edwards, D.P.; Churchill, M.E. Structure of the progesterone receptor-deoxyribonucleic acid complex: Novel interactions required for binding to half-site response elements. Mol. Endocrinol. 2006, 20, 3042-3052. [CrossRef] [PubMed]

31. Sutinen, P.; Malinen, M.; Heikkinen, S.; Palvimo, J.J. SUMOylation modulates the transcriptional activity of androgen receptor in a target gene and pathway selective manner. Nucleic Acids Res. 2014, 42, 8310-8319. [CrossRef] [PubMed]

32. Salhia, B.; Kiefer, J.; Ross, J.T.; Metapally, R.; Martinez, R.A.; Johnson, K.N.; DiPerna, D.M.; Paquette, K.M.; Jung, S.; Nasser, S.; et al. Integrated genomic and epigenomic analysis of breast cancer brain metastasis. PLoS ONE 2014, 9, e85448. [CrossRef] [PubMed]

33. Kalashnikova, E.V.; Revenko, A.S.; Gemo, A.T.; Andrews, N.P.; Tepper, C.G.; Zou, J.X.; Cardiff, R.D.; Borowsky, A.D.; Chen, H.W. ANCCA/ATAD2 overexpression identifies breast cancer patients with poor prognosis, acting to drive proliferation and survival of triple-negative cells through control of B-Myb and EZH2. Cancer Res. 2010, 70, 9402-9412. [CrossRef] [PubMed]

34. Hsia, E.Y.; Kalashnikova, E.V.; Revenko, A.S.; Zou, J.X.; Borowsky, A.D.; Chen, H.W. Deregulated E2F and the AAA+ coregulator ANCCA drive proto-oncogene ACTR/AIB1 overexpression in breast cancer. Mol. Cancer Res. 2010, 8, 183-193. [CrossRef] [PubMed]

35. Porter, S.; Span, P.N.; Sweep, F.C.; Tjan-Heijnen, V.C.; Pennington, C.J.; Pedersen, T.X.; Johnsen, M.; Lund, L.R.; Romer, J.; Edwards, D.R. ADAMTS8 and ADAMTS15 expression predicts survival in human breast carcinoma. Int. J. Cancer 2006, 118, 1241-1247. [CrossRef] [PubMed]

36. Hu, H.; Wang, J.; Gupta, A.; Shidfar, A.; Branstetter, D.; Lee, O.; Ivancic, D.; Sullivan, M.; Chatterton, R.T., Jr.; Dougall, W.C.; et al. RANKL expression in normal and malignant breast tissue responds to progesterone and is up-regulated during the luteal phase. Breast Cancer Res. Treat. 2014, 146, 515-523. [CrossRef] [PubMed]

37. Oeggerli, M.; Tian, Y.; Ruiz, C.; Wijker, B.; Sauter, G.; Obermann, E.; Guth, U.; Zlobec, I.; Sausbier, M.; Kunzelmann, K.; et al. Role of KCNMA1 in breast cancer. PLoS ONE 2012, 7, e41664. [CrossRef] [PubMed]

38. Liu, A.; He, F.; Gu, X. Identification and characterization of tyrosine kinases in anole lizard indicate the conserved tyrosine kinase repertoire in vertebrates. Mol. Genet. Genom. 2017, 292, 1405-1418. [CrossRef] [PubMed]

39. Zhao, Y.; Yang, L.; He, J.; Yang, H. STYK1 promotes Warburg effect through PI3K/AKT signaling and predicts a poor prognosis in nasopharyngeal carcinoma. Tumour Biol. 2017, 39, 1010428317711644. [CrossRef] [PubMed]

40. Bujko, M.; Kober, P.; Mikula, M.; Ligaj, M.; Ostrowski, J.; Siedlecki, J.A. Expression changes of cell-cell adhesion-related genes in colorectal tumors. Oncol. Lett. 2015, 9, 2463-2470. [CrossRef] [PubMed]

41. Palmieri, C.; Monteverde, M.; Lattanzio, L.; Gojis, O.; Rudraraju, B.; Fortunato, M.; Syed, N.; Thompson, A.; Garrone, O.; Merlano, M.; et al. Site-specific CpG methylation in the CCAAT/enhancer binding protein delta (CEBPdelta) CpG island in breast cancer is associated with metastatic relapse. Br. J. Cancer 2012, 107, 732-738. [CrossRef] [PubMed]

42. Yang, Y.; He, Y.; Wang, X.; Liang, Z.; He, G.; Zhang, P.; Zhu, H.; Xu, N.; Liang, S. Protein SUMOylation modification and its associations with disease. Open Biol. 2017, 7, 170167. [CrossRef] [PubMed]

(C) 2018 by the authors. Licensee MDPI, Basel, Switzerland. This article is an open access article distributed under the terms and conditions of the Creative Commons Attribution (CC BY) license (http:/ / creativecommons.org/licenses/by/4.0/). 